\title{
Investigation of Process Variables on Forming Forces in Incremental Sheet Forming
}

\author{
Ajay Kumar ${ }^{\# 1}$, Vishal Gulati ${ }^{\# 2}$, Parveen Kumar ${ }^{* 3}$ \\ \#Department of Mechanical Engineering, Guru Jambheshwar University of Science \& Technology, \\ Hisar 125001, Haryana, India. \\ ${ }^{1}$ E-mail: ajay.kumar30886@gmail.com \\ ${ }^{2}$ E-mail: vishal_gulati_in@yahoo.com \\ *Department of Mechanical Engineering, Rawal Institute of Engineering \& Technology, \\ Faridabad 121004, Haryana, India. \\ ${ }^{3}$ E-mail: parveenkumarme@gmail.com
}

\begin{abstract}
Manufacturing of small batch size products and prototypes are not economical using conventional forming processes as these processes require dedicated and highly specialized equipments such as forming presses, dies, and punches. Incremental Sheet Forming (ISF) process has been confirmed as quiet economical process for rapid prototyping and batch type production. In this work, process variables are investigated on axial peak forces on AA2024-O sheets. A strain gauge based dynamometer has been used to record axial peak forces during incremental process. Combination of higher wall angle and higher tool diameter leads to larger axial forces which can be limitation of the capacity of the machine tool and forming tools used in the process. Higher sheet thickness not only requires larger forming forces to form the components but also increases formability of the material.
\end{abstract}

Keyword - AA-2024, Aerospace, SPIF, Forming Force, Process Parameters.

\section{INTRODUCTION}

The Sheet metal forming is an important aspect of manufacturing industries. In manufacturing sectors, conventional sheet forming processes like deep drawing, shearing, stretch forming, bending, and blanking etc. are being used to facilitate production of components. These conventional processes need dedicated and expensive dies and tools which make the process uneconomical for batch type and rapid prototyping production. In aerospace sector, approximately 200 stamping dies are utilized every year for manufacturing a lot size of about 5000 parts. Manufacturing and inventory of theses dies make the process time consuming and costly. Multi-variety components in small batches can be manufactured at low cost with Single Point Incremental Forming (SPIF) technology which prevents limitations of traditional sheet metal forming processes [1-3]. SPIF is a truly die-less process and beautified with economical tooling cost, shorter lead time and ability to form nonsymmetrical geometries without using expensive dies. These advantages permit manufacturing of complex components of sheet metal for rapid prototyping at economical level. SPIF mainly finds its application in medical sector, aerospace and automotive industry. A simple spherical tool can be employed to produce different complex shape in SPIF process. Forming tool deforms the sheet metal layer by layer according to numerically designed tool path. Forming path of the traveling tool is most crucial for the successful forming of the components. Generally, profile and helical tool paths are employed on a CNC machine tool to obtain a desired shape. In profile tool path, the tool moves in a single plane and reaches to its initial point then it takes a step depth in the vertically downward direction. This process continues till the complete shape is formed. In SPIF, sheet is squeezed locally by the tool; hence, study of forming forces becomes much important regarding fracture mechanism and precision of the formed part. It is also important to estimate maximum forming force to ensure the safe utilization of forming hardware. Forming force is the force required to deform the sheet at the tool-sheet interface. Fig.1 shows the force components in Cartesian coordinate system. The force components Fx, Fy and Fz along $\mathrm{x}, \mathrm{y}$ and $\mathrm{z}$ directions respectively can be measured with the help of dynamometer or load cell. The measured data can be recorded with the help of data acquisition system, charge amplifier and PC based environment.

\section{LITERATURE REVIEW}

Rauch et al. [4] investigated influence of feed rate for different tool path strategies on AA5086 sheets. The forming force was found to increase with increase in feed rate. Oleksik et al. [5] investigated effects of different tool diameters $(12,16,20 \mathrm{~mm})$ on forming forces in SPIF and elaborated mathematical models. Forming forces in axial direction was much higher than those occurred in x-direction. Arfa et al. [6] studied influence of different sheet thickness for profile and spiral tool path on AA3003- O sheets by experiments and simulation with ABAQUS with a set of standard parameters. Results showed that forces increases directly with increase in 
sheet thickness for both types of tool path and there was $2 \%$ and $3 \%$ error between FEM and experimental results of forces, respectively for the smallest and greatest values of sheet thickness $(1.2 \mathrm{~mm}$ and $2 \mathrm{~mm})$. Liu et al. [7] also studied the influence of the sheet thickness on vertical forming forces. The maximum vertical force was $6792.4 \mathrm{~N}$ with $2.54 \mathrm{~mm}$ thickness and $1.5 \mathrm{~mm}$ step-down size. Aerens et al. [8] studied effects of tool diameters on AA3003 sheets and showed that tangential force $\left(\mathrm{F}_{t}\right)$ is small and remains nearly constant but force in z-direction increase with tool diameter. Al-Obaidi et al. [9] studied influences of feed rate with induction heating on forming force on DC04 sheets and showed that at $35 \mathrm{~kW}$ power and a feed rate of $2500 \mathrm{~mm} / \mathrm{min}$, force values was higher (approx. $1450 \mathrm{~N}$ ) than force value (approx. $900 \mathrm{~N}$ ) at a feed rate of $500 \mathrm{~mm} / \mathrm{min}$. Li et al. [10] investigated influence of sheet material to produce a truncated cone and a truncated pyramid by experimental tests on AA7075- O sheets. It was found that the predicted forces were in good agreement with the experimental results. Davarpanah et al. [11] experimentally examined effects of wall angle on polymer sheets using SPIF. Results showed that there is an increase in the axial forces with an increase wall angle.

Literature reveals that axial force (Fz) produced during SPIF is of great importance as it determines forming capacity of machine tool. Hence, it is necessary to investigate axial force component for safe utilization of the machine tool. SPIF is characterized with different input parameters which regulate this forming process. This die-less process is still limited in manufacturing industry due to lack of information about the effecting process variables like wall angle, tool diameter and sheet thickness etc. [12-13]. This work focuses on studying influence of sheet thickness, wall angle and tool diameter on axial peak forces on AA2024-O sheets. AA2024-O aluminum alloy finds application in aerospace and automobile industries. Conical frustums of constant wall angle have been formed with hemispherical headed forming tools. Table 1 shows the process parameters investigated with their levels. Each parameter is studied at three levels taking other process variables constant as tool diameter $11.60 \mathrm{~mm}$, wall angle $64^{\circ}$, spindle speed $1000 \mathrm{rpm}$, feed rate $1500 \mathrm{~mm} / \mathrm{min}$, sheet thickness 1.2 $\mathrm{mm}$ and step size $0.5 \mathrm{~mm}$. Castrol lubricant oil Alpha SP 320 was applied on sheet in order to reduce friction at tool-sheet interface.

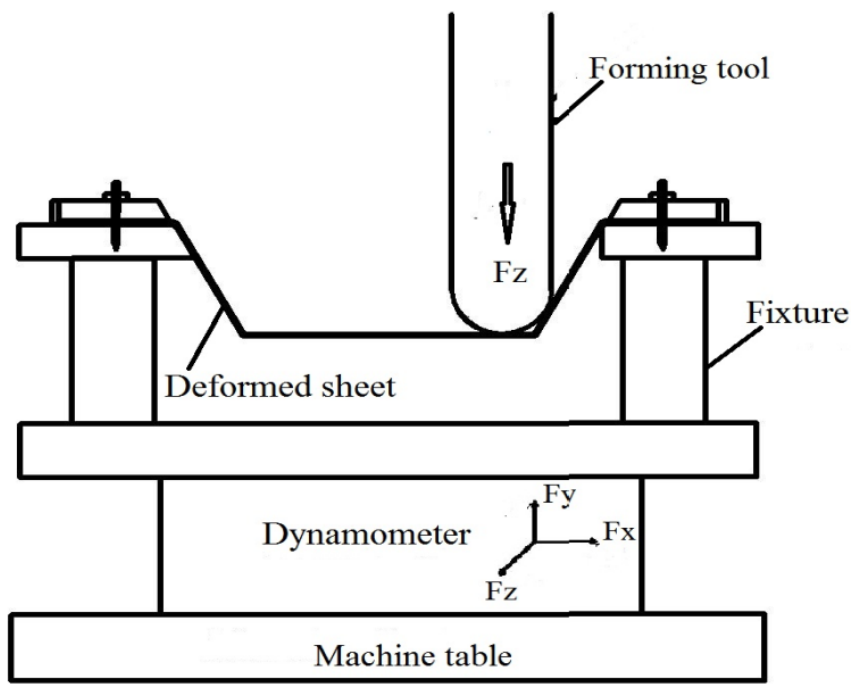

Fig. 1: Schematic representation of forming force measurement set-up

Table 1. Process parameters and their levels

\begin{tabular}{|l|l|l|l|l|}
\hline Parameter & Level 1 & Level 2 & Level 3 & Level 4 \\
\hline Tool diameter $(\mathrm{mm})$ & 7.52 & 11.60 & 15.66 & - \\
\hline Wall angle $\left(^{\circ}\right)$ & 52 & 56 & 60 & 64 \\
\hline Sheet thickness $(\mathrm{mm})$ & 0.8 & 1.0 & 1.2 & 1.4 \\
\hline
\end{tabular}

Table 2. Chemical compositions of aluminum alloy used

\begin{tabular}{|l|l|l|l|l|l|l|l|l|l|}
\hline Chemical composition (weight \%) \\
\hline AA 2024- & $\mathrm{Al}$ & $\mathrm{Cr}$ & $\mathrm{Cu}$ & $\mathrm{Fe}$ & $\mathrm{Mg}$ & $\mathrm{Mn}$ & $\mathrm{Si}$ & $\mathrm{Ti}$ & $\mathrm{Zn}$ \\
\cline { 2 - 9 } $\mathrm{O}$ & 91.50 & 0.10 & 4.60 & 0.30 & 1.70 & 0.80 & 0.50 & 0.10 & 0.20 \\
\hline
\end{tabular}




\section{III.MATERIALS AND METHODS}

Experimental work has been performed on a 3-axis VMC. Chemical compositions of AA-2024 alloy sheets are given in Table 3. Forming tools are made of HSS and hardened to 64 HRC before finishing operation. Conical frustums of $120 \mathrm{~mm}$ upper diameter and $70 \mathrm{~mm}$ height are formed for selected wall angles. Helical tool path has been used in CAM package for tool trajectory. Forming forces in axial direction (Fz) have been measured using a strain gauge based dynamometer which was mounted below the fixture as shown in Fig.2. A data logger system equipped with Microscada software has been provided to dynamometer in order to facilitate the processed force values in PC based environment. ADC 0808 analog to digital converter has been used in data logger system.

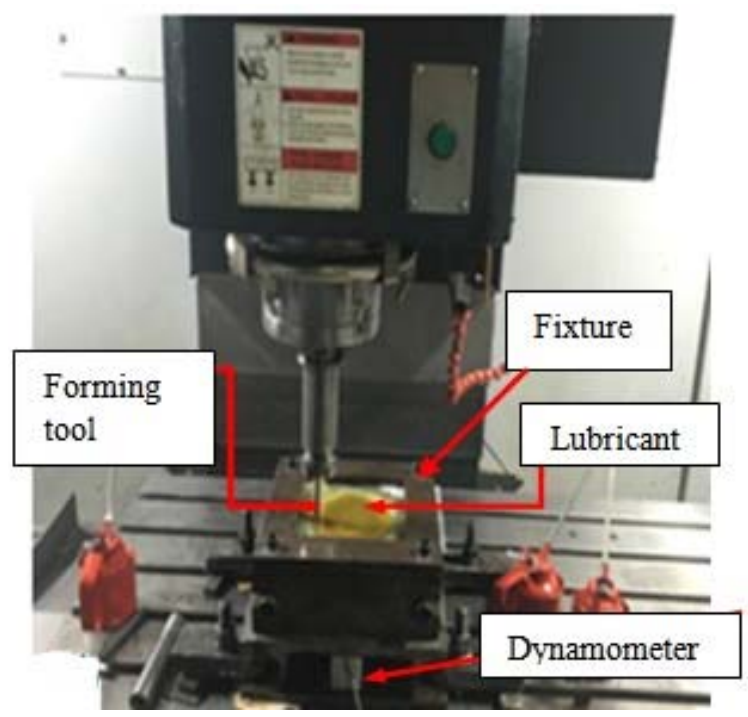

Fig. 2: Experimental set up

\section{IV.RESULTS AND DISCUSSION}

Table 3 shows the test results of experiments performed for wall angle, tool diameter and sheet thickness on axial peak forces (Fz max.). Influence of wall angle with different tool diameters has been depicted in Fig.3. Results showed that axial peak forces increases with increase in tool diameter and wall angle. For higher tool diameter, more material has to be pressed by the forming tool which leads to increase in required forming force. Similarly, for larger tool diameter, larger contact area is induced at the tool-sheet interface which results in increasing required forming force. This could become a limiting factor for hardware used for forming operation and should be avoided. Axial peak force was found to increase approximately $15.14 \%, 18.89 \%, 19.58 \%$, and $20.03 \%$ for $52^{\circ}, 56^{\circ}, 60^{\circ}$ and $64^{\circ}$ wall angles respectively when punch diameter was increased from $7.52 \mathrm{~mm}$ to $15.66 \mathrm{~mm}$. Similarly, axial peak force was increased by $26.71 \%$, 28.67\%, and 30.93\% for $7.52 \mathrm{~mm}, 11.60 \mathrm{~mm}$ and $15.66 \mathrm{~mm}$ tool diameters respectively when wall angle was increased from $52^{\circ}$ to $64^{\circ}$.

Table 3. Forming force test results with different process parameters

\begin{tabular}{|c|c|c|c|c|c|c|c|}
\hline \multicolumn{6}{|c|}{ Axial peak force test results for wall angle and } & \multicolumn{5}{c|}{$\begin{array}{c}\text { Axial peak force test results for sheet thickness and } \\
\text { tool diameter }\end{array}$} \\
\hline $\begin{array}{c}\text { Sr. } \\
\text { no. }\end{array}$ & $\begin{array}{c}\text { Wall } \\
\text { angle } \mathbf{(}^{\mathbf{(}} \mathbf{)}\end{array}$ & $\begin{array}{c}\text { Tool diameter } \\
(\mathbf{m m})\end{array}$ & $\begin{array}{c}\text { Fz max. } \\
(\mathbf{N})\end{array}$ & $\begin{array}{c}\text { Sr. } \\
\text { no. }\end{array}$ & $\begin{array}{c}\text { Sheet thickness } \\
(\mathbf{m m})\end{array}$ & $\begin{array}{c}\text { Tool diameter } \\
(\mathbf{m m})\end{array}$ & $\begin{array}{c}\text { Fz max. } \\
(\mathbf{N})\end{array}$ \\
\hline 1 & 52 & 7.52 & 661 & 13 & 0.8 & 7.52 & 709 \\
\hline 2 & 52 & 11.60 & 714 & 14 & 0.8 & 11.60 & 775 \\
\hline 3 & 52 & 15.66 & 779 & 15 & 0.8 & 15.66 & 848 \\
\hline 4 & 56 & 7.52 & 734 & 16 & 1.0 & 7.52 & 792 \\
\hline 5 & 56 & 11.60 & 814 & 17 & 1.0 & 11.60 & 875 \\
\hline 6 & 56 & 15.66 & 905 & 18 & 1.0 & 15.66 & 968 \\
\hline 7 & 60 & 7.52 & 805 & 19 & 1.2 & 7.52 & 903 \\
\hline 8 & 60 & 11.60 & 901 & 20 & 1.2 & 11.60 & 1003 \\
\hline 9 & 60 & 15.66 & 1001 & 21 & 1.2 & 15.66 & 1127 \\
\hline 10 & 64 & 7.52 & 902 & 22 & 1.4 & 7.52 & 1067 \\
\hline 11 & 64 & 11.60 & 1001 & 23 & 1.4 & 11.60 & 1200 \\
\hline 12 & 64 & 15.66 & 1128 & 24 & 1.4 & 15.66 & 1333 \\
\hline
\end{tabular}




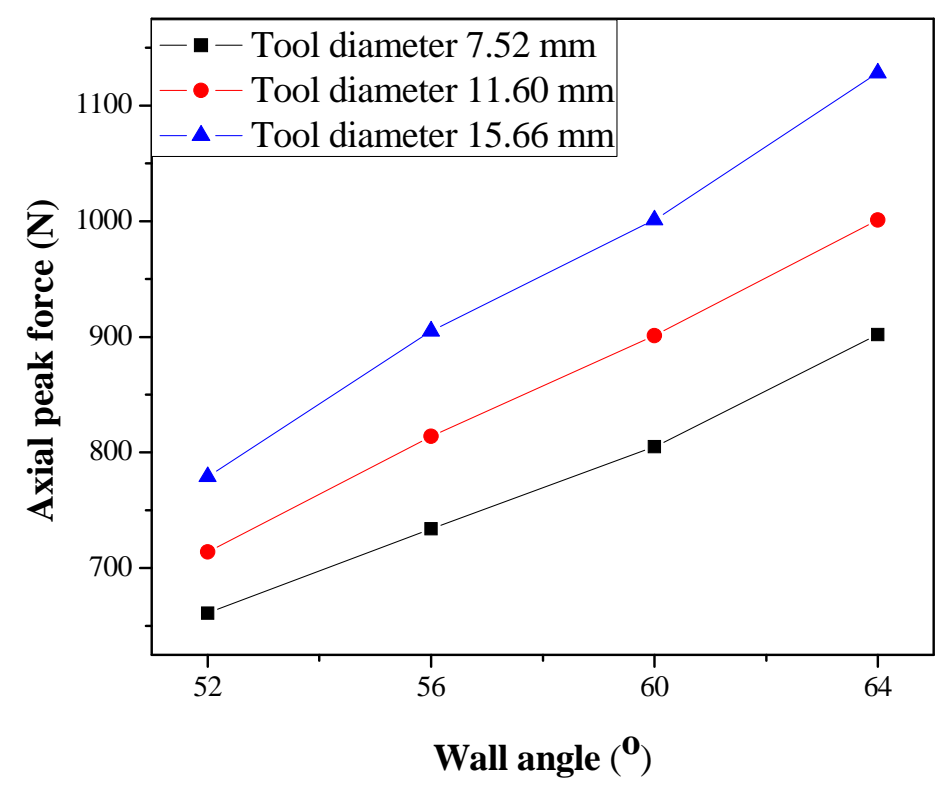

Fig. 3: Effects of wall angle and tool diameter on axial peak forces

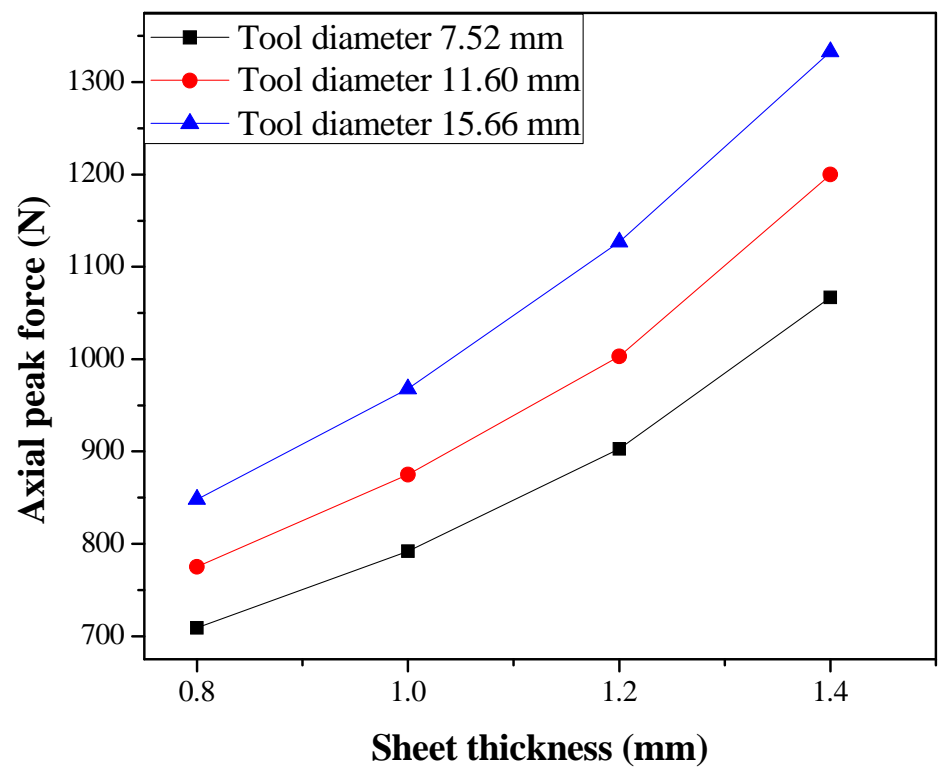

Fig. 4: Effects of sheet thickness and tool diameter on axial peak forces

Influence of sheet thickness with different tool diameters is depicted in Fig.4. Experimental results showed that axial peak force increased with increase in sheet thickness with all levels of tool diameters (7.52, 11.60, and $15.66 \mathrm{~mm}$ ). This is due to the fact that more metal is subjected to forming per pass of the punch over the sheet requiring higher forming force to form a specific shape. Moreover, sheet fracture was occurred for combination of lower thickness and smaller tool diameter because smaller punch penetrates the sheet material and less material is available for delaying the fracture. This also indicated loss of formability. Axial peak force increased approximately $16.39 \%, 18.18 \%, 19.87 \%$, and $19.95 \%$ for $0.8,1.0,1.2$, and $1.4 \mathrm{~mm}$ sheet thicknesses respectively when punch diameter was increased from $7.52 \mathrm{~mm}$ to $15.66 \mathrm{~mm}$. When sheet thickness was increased from $0.8 \mathrm{~mm}$ to $1.4 \mathrm{~mm}$, axial peak force was found to increase by $33.55 \%, 35.41 \%$, and $36.38 \%$ for $7.52 \mathrm{~mm}, 11.60 \mathrm{~mm}$ and $15.66 \mathrm{~mm}$ punch diameter respectively. 


\section{CONCLUSION}

In this study, influence of wall angle, tool diameter and sheet thickness has been investigated on axial peak forces on AA2024-O sheets experimentally using SPIF process. Conical frustums have been formed using helical tool path. Forming forces were found to increase with the increase in tool diameter, sheet thickness, and wall angle. Combination of larger tool diameter (15.66 mm in this case) and larger sheet thickness $(1.4 \mathrm{~mm}$ in this case) produced maximum peak force (Fz max. $=1333 \mathrm{~N}$, in this case) in axial direction which is a limitation to the hardware used for forming operation. Moreover, sheet fracture was occurred for combination of lower thickness and smaller tool diameter because smaller punch penetrates the sheet material and less material is available for delaying the fracture. This also indicated loss of formability. Future work would focus on analysis of formability and thickness reduction of the parts which seeks importance and suitability in setting guidelines for industrial application.

\section{REFERENCES}

[1] Q. Wang, Q. Yuan, and Y. Li, "Evaluation of forming forces in ultrasonic incremental sheet metal forming,” Aerospace Science and Technology, vol. 63, pp. 132-139, 2017.

[2] A. Mohammadi, L. Qin, H. Vanhove, M. Seefeldt, A. Van Bael, and J. R. Duflou, "Single Point Incremental Forming of an Aged ALCu-Mg Alloy: Influence of Pre-heat Treatment and Warm Forming,” Journal of Materials Engineering and Performance, vol. 25, pp. 2478-2488, 2016.

[3] M. Rauch, J. Y. Hascoët, J. C. Hamann, and Y. Plennel, “A new approach for toolpath programming in Incremental Sheet Forming,” International Journal of Material Forming, vol. 1, pp. 1191-1194, 2008.

[4] V. Oleksik, A. Pascu, A. Gavrus, and M. Oleksik, "Experimental studies regarding the single point incremental forming process," Academic Journal of Manufacturing Engineering, vol. 8, pp. 51-56, 2010.

[5] H. Arfa, R. Bahloul, and H. BelHadjSalah, "Finite element modelling and experimental investigation of single point incremental forming process of aluminum sheets: influence of process parameters on punch force monitoring and on mechanical and geometrical quality of parts,” International journal of material forming, vol. 6, pp. 483-510, 2013.

[6] Z. Liu, Y. Li, and P. A. Meehan, "Experimental investigation of mechanical properties, formability and force measurement for AA7075-O aluminum alloy sheets formed by incremental forming," International Journal of Precision Engineering and Manufacturing, vol. 14, pp. 1891-1899, 2013.

[7] R. Aerens, P. Eyckens, A. Van Bael, and J. R. Duflou, "Force prediction for single point incremental forming deduced from experimental and FEM observations,” The International Journal of Advanced Manufacturing Technology, vol. 46, pp. 969-982, 2010.

[8] A. Al-Obaidi, V. Kräusel, and D. Landgrebe, "Hot single-point incremental forming assisted by induction heating," The International Journal of Advanced Manufacturing Technology, vol. 82, pp. 1163-1171, 2016.

[9] Y. Li, W. J. Daniel, Z. Liu, H. Lu, and P. A. Meehan, "Deformation mechanics and efficient force prediction in single point incremental forming,” Journal of Materials Processing Technology, vol. 221, pp. 100-111, 2015.

[10] M. A. Davarpanah, A. Mirkouei, X. Yu, R. Malhotra, and S. Pilla, "Effects of incremental depth and tool rotation on failure modes and microstructural properties in Single Point Incremental Forming of polymers," Journal of materials processing technology, vol. 222, pp. 287-300, 2015.

[11] G. Ambrogio, L. De Napoli, L. Filice, F. Gagliardi, and M. Muzzupappa, "Application of IF process for high customised medical product manufacturing,” Journal of materials processing technology, vol. 162, pp. 156-162, 2005.

[12] M. C. Radu, and I. Cristea, "Processing Metal Sheets by SPIF and Analysis of Parts Quality," Materials and Manufacturing Processes, vol. 28, pp. 287-293, 2013.

\section{AUTHOR PROFILE}

Ajay Kumar received his B.Tech degree in Mechanical Engineering and M.Tech degree in Manufacturing and Automation. Now, he is a Ph.D student in Guru Jambheshwar University of Science \& Technology, Hisar, India.

Vishal Gulati received his B.Tech and M.Tech degree in Mechanical Engineering. He completed his Ph.D in Mechanical Engineering from NIT, Kurukshetra, India. Now, he is Professor in Mechanical Engineering in Guru Jambheshwar University of Science \& Technology, Hisar, India.

Parveen Kumar received his B.Tech degree in Mechanical Engineering from Kurukshetra University, India and M.Tech degree in Manufacturing and Automation. Now, he is an Assistant Professor in Rawal Institute of Engineering \& Technology, Faridabad, India. 